\title{
Interactions between Nod-like receptors and intestinal bacteria
}

\author{
Marcel R. de Zoete ${ }^{1}$ and Richard A. Flavell ${ }^{1,2}$ * \\ ${ }^{1}$ Department of Immunobiology, Yale University School of Medicine, New Haven, CT, USA \\ ${ }^{2}$ Howard Hughes Medical Institute, Yale University, New Haven, CT, USA
}

\section{Edited by:}

Jorg Hermann Fritz, McGill University,

Canada

Reviewed by:

Axel Lorentz, University of

Hohenheim, Germany

Juan J. Garcia-Vallejo, VU University

Medical Center, Netherlands

${ }^{*}$ Correspondence:

Richard A. Flavell, Department of

Immunobiology, Yale University

School of Medicine, 300 Cedar

Street, TAC S-569, New Haven, CT

06520, USA

e-mail: richard.flavell@yale.edu
Nucleotide oligomerization domain (Nod)-like Receptors (NLRs) are cytosolic sensors that mediate the activation of Caspase- 1 and the subsequent processing and secretion of the pro-inflammatory cytokines IL-1 $\beta$ and IL-18, as well as an inflammatory cell death termed pyroptosis. While a multitude of bacteria have been shown to activate one or more NLRs under in vitro conditions, the exact impact of NLR activation during the course of colonization, both of pathogenic and commensal nature, is less understood. In this review, we will focus on the role of intestinal NLRs during the various stages of infection with common gastrointestinal bacterial pathogens, as well as NLR function in controlling and shaping the microbiota.

Keywords: nod-like receptors, microbiota, inflammasome, intestine, pathogen

\section{INTRODUCTION}

The human body lives in symbiosis with trillions of microbial cells, collectively called the microbiota, with the vast majority of these microbes being bacteria that inhabit the gastrointestinal tract (1). This symbiosis begins with colonization of the gastrointestinal tract at birth and then is sustained throughout life by environmental exposures (2). Occasionally this microbial symbiosis is challenged by invading bacterial pathogens, which perturb the microbial ecosystem and cause disease.

Our ability to harbor trillions of bacteria within our intestines relies on the maintenance of a safe distance between these bacteria and the single layer of intestinal epithelial cells. Crucial protective mechanisms have evolved to help ensure host-bacteria mutualism. A major barrier bacteria encounter in the intestine is formed by the mucus layer, a dense network of glycoproteins that most bacteria are unable to breach (3). To further aid the barrier function of the mucus layer, intestinal cells also secrete an array of antimicrobial proteins, like antimicrobial peptides, lectins, and lysozymes. Furthermore, secreted IgA specifically targets bacteria for immune exclusion (4).

At the cellular level, sensing systems continuously scan for bacteria that are able to actively surpass the mucus layer and attach to and/or invade the epithelium. Two major receptor families that detect microbes are the Toll-like Receptors (TLRs), which control the extracellular compartment, and Nod-like Receptors (NLRs), which sense the presence of intracellular microbes (5). NLRs are crucial for fighting and resolving infections as many pathogenic bacteria (and under certain conditions also members of the commensal microbiota) attempt to exploit and enter the cytosol for nutrients and to escape extracellular threats (6). Here, we provide an overview of the role of NLRs in protection against intestinal pathogenic bacteria and control of the intestinal microbiota.

\section{INTESTINAL NLRS}

Nod-like receptors generally consist of a ligand-sensing domain in the form of a Leucine Rich Repeat (LRR) domain, a central ATP binding domain, and a signaling domain (often in the form of a CARD or Pyrin domain) and are categorized by their domain structure. While NLRs are expressed widely in a variety of tissues in humans and mice, we will focus in this review on those that were shown to function in the defense against bacteria in the intestine. While Absent In Melanoma 2 (AIM2) theoretically is not part of the NLR family, we have included it here for completeness.

\section{NOD1 AND NOD2 (NLRC1, NLRC2)}

The pattern recognition receptors NOD1 and NOD2 are amongst the best-studied NLRs, and their ligands are well defined. Both NOD1 and NOD2 sense cytosolic bacterial peptidoglycan fragments with high specificity: NOD1 is activated by D-glutamylmeso-diaminopimelic acid (DAP) containing peptidoglycan fragments, which are mainly found in Gram-negative bacteria (7), whereas NOD2 was shown to bind and responds to muramyl dipeptide (MDP), found in all bacteria (8). Despite the presence of N-terminal CARD domains, NOD1 and NOD2 are noninflammasome forming NLRs and do not seem to directly activate Caspase-1. Instead, after ligand binding the CARD domain of NOD1 and NOD2 interacts with the signaling kinase RIP2 (RIPK2, $\mathrm{RICK}$ ) that initiates a signaling cascade resulting in NF- $\mathrm{KB}$ activation, as well as the activation of ERK, p38 and mitogen-activated protein kinases (MAPKs) $(9,10)$. These signaling pathways result in the expression of a variety of pro-inflammatory cytokines and chemokines, as well as the production of reactive oxygen species. While NOD2 expression is more restricted, both NODs are expressed in macrophages, dendritic cells, Paneth cells, and intestinal epithelial cells, making them highly suited to sense infections throughout the intestinal tract (10). In recent years, several 
layers of complexity were added onto the basic mechanism of NOD1 and NOD2 sensing and signaling. For instance, NOD2 was shown to interact with NLRP1, NLRP3, and NLRP12 (11), NOD1 and NOD2 were found to play a role in autophagy (12), and NOD1 senses the modification of small rho GTPases injected by Salmonella during infection (13).

\section{NLRC4}

NLRC4 is an N-terminal CARD domain containing NLR. The elucidation of the NLRC4 crystal structure has revealed that, under resting conditions, NLRC4 resides in a closed monomeric form, kept in place by an ADP-dependent autoinhibitory mechanism involving multiple domains including the LRR (14). Ligand binding is proposed to induce "opening" of the structure, the exchange of ADP for ATP, and subsequent NLRC4 oligomerization. Phosphorylation of a conserved serine residue proximal to the LRR was shown to be required for NLRC4 inflammasome activation in macrophages, although the exact role in this process requires further investigation (15). NLRC4 responds to attaching or invading pathogens by sensing their bacterial secretion systems. So far, two bacterial ligands are well defined: flagellin, which is co-secreted with virulence factors either through type III or type IV secretion systems (T3SS and T4SS, respectively) (16-18), and PrgJ, a structural component of the type III secretion system that leaks or is secreted into the host cytosol (19). Within the cytosol, flagellin and PrgJ bind to the adapter proteins NLR family, apoptosis inhibitory protein (NAIP) 2 and NAIP5, respectively $(20,21)$, which subsequently bind NLRC4 to initiate its oligomerization into a ring-like inflammasome that recruits the adapter protein apoptosis-associated speck-like protein containing a CARD (ASC) (containing both a Pyrin and CARD domain) and Caspase-1 (22). This complex then processes the pro-inflammatory cytokines proIL-1 $\beta$ and pro-IL-18, and induces pyroptosis, an inflammatory form of cell death. Interestingly, unlike mice, humans have only one NAIP protein, which is unresponsive to both flagellin or basal rod protein but instead binds the conserved T3SS needle protein to activate NLRC4 (20).

\section{NLRP3}

While NLRP3 is probably the best studied of the NLRs, the mechanism of receptor activation remains relatively unclear. NLRP3, or cryopyrin, was originally shown to play a key role in a collection of autoinflammatory disorders collectively termed cryopyrinassociated periodic syndromes, which all share mutations in NLRP3 that lead to inappropriate IL-1 $\beta$-mediated inflammatory responses (23). NLRP3 was subsequently found to "sense" a long list of ligands or stimuli, including ATP, pore-forming toxins, particulates like asbestos and silica, bacteria, viral, and fungal infections (24). Initially, three main theories of the activation of NLRP3 were proposed: potassium efflux, lysosomal rupture and subsequent cleavage by released Cathepsin, and ROS production. Several "second generation" unifying NLRP3 ligands were proposed to combine the three, including oxidized mitochondrial DNA released into the cytosol following mitochondrial damage (25); thioredoxin-interacting protein (26), calcium mobilization (27), mitochondrial cardiolipin (28), and changes in cell volume (29). While most of these NLRP3 ligands were recently shown to lead to potassium efflux might, suggesting this to be the common trigger in the end (30), NLRP3 activation remains enigmatic; structural studies similar to those done for NLRC4 might eventually elucidate the elusive NLRP3 ligand.

A new chapter for NLRP3 has been opened through the elucidation of the non-canonical inflammasome pathway. Due to the (re)discovery of the presence of a mutated, non-functional Caspase-11 in the original Caspase-1-deficient mouse, a role for Caspase-11 was found in NLRP3-inflammasome activation by Gram-negative bacteria (31). After prolonged ( 17h) stimulation of bone-marrow macrophages with bacteria, Caspase11 was shown to be activated, leading to cell death and NLRP3/ASC/Caspase-1-dependent IL-1 $\beta$ and IL-18 secretion. It was subsequently shown that the TLR4-TRIF-Type I Interferon pathway was required to induce high levels of Caspase-11 transcription needed for non-canonical inflammasome activation (32). However, it recently was shown that intracellular LPS serves as a ligand able to activate the non-canonical inflammasome pathway, independently of increasing levels of Caspase-11 caused by Type I Interferon (33). Three major questions regarding noncanonical inflammasome activation remain currently unanswered: what is the receptor that senses intracellular LPS or potentially other ligand (presumably a CARD-containing NLR), how does this complex feed into the NLRP3 inflammasome (Caspase11-dependent pyroptosis resulting in potassium efflux?), and is Caspase- 11 activated by any additional receptors?

\section{NLRP6}

NLRP6 falls within the group of NLRs that was initially found to induce NF- $\mathrm{KB}$ and Caspase-1 activation during overexpression in transfected tissue culture cells (34). In this system, human NLRP6 was also shown to form punctate structures in the cytoplasm, but only in the presence of ASC, suggesting the ability of NLRP6 to form inflammasomes or inflammasome-like structures. Unlike in humans, where NLRP6 is not highly or widely expressed, mice exhibit high NLRP6 expression throughout the intestine, kidneys, and liver $(35,36)$, which can be regulated by stress factors (37). Mechanistically, NLRP6 was shown to be a negative regulator of NF- $\mathrm{B}$ and MAPK in cultured bone-marrow macrophages from NLRP6-deficient mice (38), which is the opposite of what was initially observed in overexpression studies. NLRP6 function as a negative regulator of NF- $\mathrm{B}$ and MAPK might play a role in the increased intestinal tissue proliferation and inflammation observed in NLRP6-deficient mice $(39,40)$. Furthermore, NLRP6 was shown to be involved in the production of Caspase-1 dependent IL-18 (36), again suggesting the ability of NLRP6 to form an inflammasome.

\section{NLRP12}

Since its identification, NLRP12 has been assigned a number of different functions. Like NLRP6, NLRP12 was originally described to induce NF- $\kappa \mathrm{B}$ and Caspase-1 activation when coexpressed with ASC (41). In contrast, without ASC co-expression, NLRP12 overexpression reduced non-canonical NF- $\kappa \mathrm{B}$ activation and enhanced the expression of non-classical and classical MHC class I genes (42-44). NLRP12-deficient mice were also reported to have defective dendritic cell and neutrophil responses 
to chemokines and subsequent defective dendritic cell migration to draining lymph nodes (45). In addition, NLRP12-deficiency led to enhanced colon inflammation and colorectal cancer development due to increased (non-canonical) NF- $\mathrm{B}$ and ERK activation $(46,47)$, similar to what was observed previously for NLRP6.

\section{AIM2}

AIM2 was originally identified in humans as an interferoninducible, putative tumor suppressor protein (48), but subsequently found to sense cytoplasmic double stranded (ds) DNA, form an inflammasome complex together with ASC and Caspase1 , and trigger the processing of pro-IL-1 $\beta$ and pro-IL-18 (49-52). Like NLRP receptors, AIM2 contains an N-terminal signaling Pyrin domain; however, the C-terminal consists of a DNA-binding HIN200 domain. AIM2 is able to sense the presence of cytosolic non-sequence-specific dsDNA of both viral and bacterial origin. Bacterial DNA enters the cytosol mainly by a passive process following bacterial lysis, for instance during rapid cytosolic bacterial replication or after intracellular bacteria-containing vesicles are compromised, but appears to be always preceded by bacterial invasion into the host cell, making AIM2 a specific sensor for intracellular bacteria and viruses (53-55). In a mechanism similar to what was observed for NLRC4, the HIN200 domain functions as a negative regulator of the signaling Pyrin domain. Non-sequence-specific binding of dsDNA releases this inhibition, liberating the Pyrin domain to recruit ASC and Caspase-1, and form an inflammasome surrounding the released bacterial or viral DNA $(56,57)$.

\section{ENTERIC PATHOGENS AND THEIR INTERACTIONS WITH NLRs}

Foodborne gastrointestinal pathogens are a major cause of bacterial infections in humans (58). Studies on these pathogens, both in the human host and in various murine models, have provided great insights into microbial virulence mechanisms as well as the immunological defense strategies of the host. For NLRs, pathogenhost interactions have been of great value for the elucidation of the different functions of this family of innate sensors, both in in vitro and in vivo model systems. Below (and summarized in Table 1), we provide an overview of the role of NLRs during infections with the most commonly studied bacterial enteric pathogens.

\section{SALMONELLA}

In humans, infections with the Gram-negative bacterium Salmonella enterica (S. enterica) generally result in one of two distinct clinical phenotypes. S. enterica serovars Typhi and Paratyphi are

Table 1 | Role of NLRs in intestinal bacterial infections.

\begin{tabular}{|c|c|c|c|c|}
\hline Bacteria & Model & NLR & Mechanism of action & Reference \\
\hline \multirow[t]{8}{*}{ S. typhimurium } & Systemic & NLRC4 & Flagellin/T3SS-induced pyroptosis, IL-1 $\beta$, and IL-18 production & $(79-81)$ \\
\hline & & NLRP3 & Caspase-1 activation & (79) \\
\hline & Systemic, T3SS-1-independent & NOD1 & Nitric oxide production in dendritic cells & (69) \\
\hline & Systemic and colitis in Balb/c & NLRC4 & IL-1 $\beta$-mediated neutrophil recruitment & (84) \\
\hline & Colitis & NLRC4 & IL-1 $\beta$ and IL-18 production & $(80)$ \\
\hline & & NOD1 & NOD1-mediated detection of SipA & $(70)$ \\
\hline & Colitis, T3SS-1-independent & NOD $1 / 2$ & Innate $\mathrm{CD}^{+}{ }^{+} \mathrm{T}$ helper type 17 cell responses in the cecum & $(74,75)$ \\
\hline & Systemic (intraperitoneal) & NLRP6 & NLRP6-mediated negative regulation of NF- $\mathrm{KB}$ and MAPK activation & $(38)$ \\
\hline \multirow[t]{4}{*}{ C. rodentium } & Colitis & NOD2 & $\begin{array}{l}\text { NOD2-activation in stromal cells, CCL2/CCR2-dependent recruitment } \\
\text { of inflammatory monocytes, IL-12-mediated bacterial clearance }\end{array}$ & (92) \\
\hline & & NOD1/2 & IL-6-dependent IL-17 production in the cecum & $(75)$ \\
\hline & & NLRC4 & $\mathrm{IL}-1 \beta$ and IL-18 production & (94) \\
\hline & & NLRP3 & IL-1 $\beta$ and IL-18 production & (94) \\
\hline \multirow[t]{3}{*}{ H. pylori } & Gastritis & NOD1 & $\begin{array}{l}\text { T4SS-mediated delivery of peptidoglycan, NF-кB-mediated } \\
\text { inflammatory responses }\end{array}$ & $(108)$ \\
\hline & & Unknown & $\begin{array}{l}\text { IL-18-dependent IL-17 production, T-cell-mediated antibacterial } \\
\text { responses }\end{array}$ & $(110,112)$ \\
\hline & & Unknown & IL-1 $\beta$-dependent impaired bacterial clearance & $(111,113)$ \\
\hline \multirow[t]{6}{*}{ Microbiota } & Colitis (DSS) & NLRP6 & $\begin{array}{l}\text { IL-18/CCL5 production, increased intestinal epithelial proliferation and } \\
\text { tissue repair }\end{array}$ & $(36,40)$ \\
\hline & & NLRP3 & Both increased and decreased susceptibility; microbiota-dependent? & $\begin{array}{l}(124,125 \\
127,128)\end{array}$ \\
\hline & & NOD1/2 & Induction of E-cadherin and Regl|I- $\gamma$ expression & $(120)$ \\
\hline & Colorectal cancer (DSS-AOM) & NLRP6 & $\begin{array}{l}\text { IL-18/CCL5/IL-6 mediated increased intestinal epithelial proliferation } \\
\text { and tissue repair }\end{array}$ & $(39,40,116)$ \\
\hline & & NLRP3 & Caspase-1 activation & $(126)$ \\
\hline & Non-alcoholic fatty liver disease & NLRP3/6 & IL-18-mediated control of microbiota & $(117)$ \\
\hline
\end{tabular}


the causative agents of Typhoid fever, a life-threatening disease characterized by systemic spread of ingested bacteria, high fever, and intestinal bleeding that results in 200,000-600,000 deaths worldwide each year (59). The more common non-typhoidal $S$. enterica serovars, like S. typhimurium and S. enteritidis, cause a selflimiting gastroenteritis characterized by (bloody) diarrhea, fever, abdominal cramps, and vomiting that usually lasts 4-7 days and affects over 90 million people worldwide each year (60).

Two different disease models in mice represent the two clinical manifestations of Salmonella infections. The classical murine model of systemic S. typhimurium infection induces a disease similar to Typhoid fever. In this model, orally administered salmonellae reach the distal ileum within hours of ingestion and, aided by flagella-mediated motility and chemotaxis (61), cross the mucus layer toward the epithelium. Here, the bacteria target the follicularassociated epithelium overlying the Peyer's Patches, with a strong preference for the M-cells, as a main port of entry. To gain access into the host cell, Salmonella employs the first of two type III secretion systems (T3SS-1), which is only expressed during this initial phase of infection, and injects an array of effector proteins into the host's cytosol that induce cytoskeletal rearrangements leading to bacterial invasion (62). Other effector proteins and the activation of pattern recognition receptors initiate inflammatory responses that attract neutrophils, monocytes, and macrophages. Salmonella replicates within the Peyer's Patches and disseminates to mesenteric lymph nodes (MLN), liver, and spleen within infected monocytes and dendritic cells. In a T3SS-1-independent manner, a small proportion of the bacteria is also taken up passively from the lumen by $\mathrm{CD} 11 \mathrm{c}^{+} \mathrm{CX} 3 \mathrm{CR} 1^{+}$dendritic cells and transported directly to the MLN, bypassing the Peyer's Patches (63). To survive and replicate in the host's cells, Salmonella resides within a vacuole, the Salmonella-containing Vacuole (SCV), whose integrity is maintained by the effector proteins secreted into the cytosol through a second T3SS (T3SS-2). During the later stages of disease, disseminated bacteria in the liver and spleen are found mostly within macrophages, in which they rapidly replicate. Continuous cycles of bacterial replication and dissemination eventually lead to bacteremia from which mice succumb after a week.

In the murine colitis model, infection with Salmonella is preceded by a single dose of streptomycin, which is believed to briefly reduce "colonization resistance" provided by the microbiota that occupies the more distal intestinal tract and strongly competes for nutrients. In this short window, Salmonella is able to gain a foothold in the cecum and colon, and replicates to high numbers within hours of infection, limiting the need for systemic spread (64). Colonization is accompanied by mucosal penetration of bacteria and the development of colitis, similar to the pathology seen in human infection with non-typhoidal serovars. For efficient colonization salmonellae still require T3SSs, which mediate invasion of enterocytes and induction of (local) inflammation. A reason for this was presented in an elegant study by Winter et al. which revealed that T3SS-induced inflammatory responses are actively exploited by Salmonella through the ability to utilize tetrathionate, formed in the intestine under inflammatory conditions, to successfully compete with the microbiota (65). In the colitis mouse model, Salmonella also exploits a T3SS-1-independent, "passive" route for uptake through $\mathrm{CD} 11 \mathrm{c}^{+} \mathrm{CX} 3 \mathrm{CR} 1^{+}$dendritic cells. Similar to what is seen in the systemic model, these two invasion pathways act in concert, although T3SS-1-mediated invasion seems much more dominant. While bacteria are able to grow extensively in the distal intestine in the colitis model, substantial numbers of bacteria still continue to disseminate to liver and spleen, and infected mice usually die after 5-6 days.

As several phases of infection largely rely on cellular invasion, NLRs appear to be the ideal sensing mechanism for Salmonella. In vitro, Salmonella is sensed by NOD2 in cultured intestinal epithelial cells, which enables the control of intracellular bacteria though the induction of antimicrobial responses and autophagy (66-68), and by NOD1 in bone-marrow-derived dendritic cells, resulting in nitric oxide production (69). Interestingly, while Salmonella peptidoglycan may be involved in the activation of NOD1 and NOD2, it was recently shown that the modification of small Rho GTPases by the T3SS-1 effector SopE, which enables bacterial invasion, is a danger signal sensed by NOD1 (13). Presumably through a similar mechanism, another T3SS-1 effector SipA activated NOD1/NOD2-dependent NF- $\mathrm{B}$ responses both in vitro and in vivo (70). In addition to NOD1 and NOD2, Salmonella is efficiently sensed by NLRC4, both via flagellin and the basal rod protein PrgJ, which leads to rapid pyroptosis and secretion of IL-1 $\beta$ and IL-18 by cultured macrophages, dendritic cells and B-cells $(16,17,19,71,72)$. These responses are solely dependent on T3SS-1, which is expressed only at the early logarithmic phase of bacterial cultures and is believed to represent the early phase in infection when Salmonella needs to invade host cells. The T3SS-2, expressed only at the late logarithmic phase, does not contribute to NLRC4 activation as flagellin expression is now repressed and the T3SS-2 apparatus is not recognized (19). Finally, Salmonella has been shown to activate the non-canonical NLRP3 inflammasome through Caspase-11 in macrophages (73).

In vivo, the role of NLRs during Salmonella infection has been rather difficult to define, mainly because of differences in experimental models (systemic versus colitis murine models), variations in growth phase of Salmonella at time of infection (T3SS-1-expressing versus T3SS-2-expressing conditions), different mouse intestinal microbiotas, and because of the redundancy in innate receptors. These issues are clearly demonstrated when studying NOD1 and NOD2. Both of these NLRs were shown to be dispensable during systemic infection (69). However, under T3SS-1-independent conditions, during which the bacteria "passively" cross the epithelial barrier through uptake and transport by dendritic cells, NOD1 deficiency led to higher bacterial loads and mortality. The authors show that NOD1-deficient $\mathrm{CD}_{11} \mathrm{~b}^{+} \mathrm{CD} 11 \mathrm{c}^{+}$dendritic cells contain higher numbers of Salmonella, likely because of a diminished NOD1-mediated nitric oxide response. Similarly, during Salmonella colitis, NOD1/NOD2 double knockouts or RIP2 deficient mice exhibited reduced inflammation accompanied by increased mucosal colonization and reduced early IL-17 responses of innate $\mathrm{CD}^{+}{ }^{+} \mathrm{T}$ helper type 17 cells in the lamina propria of the cecum, but again only when Salmonella was grown under T3SS-2-expressing conditions $(74,75)$; when T3SS- 1 was expressed at the time of oral infection in this model, no differences as compared to wild-type mice were observed (76). These data suggest that only one of the two major entry pathways exploited by Salmonella is controlled by NOD1/NOD2 signaling. 
During "normal" infections, however, the T3SS-1-mediated invasion seems to outweigh the alternative invasion route, leaving NOD1 and NOD2 to play a non-significant role. Interestingly, NOD1/NOD2-activation by the T3SS-1 effector SipA was shown to lead to a higher gut inflammation score in the colitis model as compared to mice lacking the receptors (70). Combined, the above-mentioned studies suggest that NOD1 and NOD2 mediated detection of Salmonella plays a specific but minor role during salmonellosis. As a further complication, differences in microbiota from wild-type and knockout mice dramatically impact Salmonella susceptibility, as demonstrated by Kaiser et al.; when "microbiota-matched" littermate controls were used (instead of independently bred or purchased wild-type mice) to test the role of RIP2 during Salmonella colitis, the initially observed difference in Salmonella-induced pathology was completely lost (64).

Caspase-1 has been shown in several publications to provide moderate protection against Salmonella infection. Without Caspase-1, mice succumb to bacteremia sooner and have higher bacterial loads in the MLN, liver and spleen in the typhoid model of infection, and more colitis accompanied by increased bacterial mucosal infiltration $(77,78)$. While NLRC4 appeared to be the main upstream candidate for caspase-1 activation, NLRC4deficient mice showed only minor or no defects in bacterial control during infections $(77,79,80)$. Two critical findings explained this "lack" of NLRC4 function in vivo; first, Salmonella actively evades recognition by NLRC4 by downregulating both T3SS-1 and flagellin as soon as the bacteria have invaded the host cell, and T3SS-2 is not recognized by NLRC4 $(19,81)$. The in vivo consequence of NLRC4-evasion, and thereby the role of NLRC4 in protection against invading pathogens, was elegantly shown by Miao et al.: when Salmonella was forced to continuously express flagellin, 100 times less bacteria were found in the spleen after $48 \mathrm{~h}$ during systemic infection. The increased control of bacterial spreading was attributed to NLRC4-mediated macrophage pyroptosis at peripheral sites, which resulted in release of the intracellular bacteria and subsequent clearance by infiltrating neutrophils (81).

NLR redundancy is a second reason why NLRC4-deficient mice do not phenocopy Caspase-1-deficient mice. Late logarithmic, non-T3SS-1 expressing salmonellae are able to activate the non-canonical Caspase-11/NLRP3 inflammasome (73). Similar to NLRC4, deficiency in only NLRP3 does not lead to differences in Salmonella infection. However, deletion of both NLRC4 and NLRP3 recapitulates the Caspase-1 phenotype completely, confirming a role for both NLRC4 and NLRP3 during Salmonella infection (79). This also demonstrates that, as was predicted by in vitro studies, NLRC4-evasion is not perfect. While pyroptosis has a clear impact on infection, the cytokines IL-1 $\beta$ and IL-18 appear to play minor roles in the control of the bacteria, since IL-1 $\beta$ and IL-18-deficent mice show little delay in bacteremia at $72 \mathrm{~h}(81,82)$.

With the realization that the Caspase- $1 \mathrm{KO}$ was in fact a Caspase-1/Caspase-11 double knockout, and the elucidation of the role of Caspase-11 in non-canonical inflammasome activation, Caspase-11-deficient mice were predicted to result in more bacterial spread due to diminished control of infection. However, Caspase-11-deficient mice were indistinguishable from WT mice during Salmonella infection (79). Surprisingly, Caspase-1 single deficient mice had even higher numbers of bacteria in liver and spleen than the Caspase-1/Caspase-11-deficient mice, suggesting a protective role for Caspase-11 deficiency, but only in the context of Caspase-1-deficiency. A potential explanation for this may be that, while rapid Caspase-1-mediated pyroptosis clears bacteria, Caspase-11-mediated pyroptosis at later time points is actively used by Salmonella to escape the "full" macrophage after extensive replication. Indeed, Caspase-11 senses bacteria escaping from or leaking out of vacuoles into the cytoplasm (83). In the absence of Caspase-1, NLRC4 "evasion" by Salmonella is complete, resulting in uncontrolled replication until Caspase-11 is utilized to break out of the macrophage and invade new host cells. Why non-canonical Caspase-11-mediated pyroptosis, like NLRC4-activation accompanied by IL- $1 \beta$ and IL-18 secretion that induces local inflammation and attracts neutrophils, is less potent than Caspase-1mediated pyroptosis in controlling Salmonella infection remains thus far unclear.

Unlike in C57BL/6 mice, in Balb/c mice NLRC4 appears to have a more prominent function in controlling Salmonella infection. In these mice, NLRC4-deficiency leads to more systemic bacterial dissemination and mortality, while less inflammation-induced pathology in the cecum was observed (84). It was subsequently shown that Salmonella specifically activates intestinal phagocytes that respond by producing IL- $1 \beta$ which triggered the upregulation of endothelial adhesion molecules. The basis of the interesting differential function of NLRC 4 between $\mathrm{C} 57 \mathrm{BL} / 6$ and Balb/c remains to be determined.

\section{ATTACHING AND EFFACING ENTERIC PATHOGENS: CITROBACTER, EPEC AND EHEC}

Citrobacter rodentium (C. rodentium), Enteropathogenic Escherichia coli (EPEC), and Enterohemorrhagic Escherichia coli (EHEC) are Gram-negative extracellular enteric pathogens that share a similar virulence strategy, termed attaching and effacing (A/E) (85, 86). EPEC and EHEC are human pathogens; EPEC is a major cause of diarrhea in young children, generally without major complications, while EHEC infections can vary greatly in severity, ranging from mild gastroenteritis to severe hemorrhagic colitis and hemolytic uremic syndrome. C. rodentium is a natural mouse pathogen resulting in self-limiting enteritis. While very little is known about activation of NLRs by EPEC and EHEC in humans, several studies have elucidated the role of such responses during infection of their murine counterpart, C. rodentium.

Within a couple of hours after oral infection of mice, $C$. rodentium reaches its initial site of infection, the lymphoid tissue in the cecum termed the cecal patch, where it reaches high density over the following 3 days (87). The cecal patch is structurally similar to the Peyer's Patch and, because of their nature as antigen sampling hotspots with decreased mucus layer thickness and absence of microvilli, provide "easy access/entrance" for several intestinal pathogens (including Salmonella, as described above). From day 3 to 4 , C. rodentium starts to spread throughout the distal colon (87). Mouse-adapted strains of C. rodentium largely skip the cecal patch phase and colonize the colon readily, suggesting that colonization of the cecal patch also serves as an adaptation phase to the mouse intestinal environment (88). Depending on the strain of $C$. rodentium used, bacterial numbers peak between day 5 and 14 with 
limited systemic spread to the MLN, liver, and spleen. The colonization then slowly diminishes until bacterial clearance from the cecum and subsequently the colon after 3-4 weeks post infection.

Upon reaching the cell surface of the cecum and colon, $C$. rodentium employs a T3SS which injects an array of virulence factors into the host's cytosol that result in the attachment of the bacteria to the enterocytes and the accompanying local destruction of the brush border microvilli of the epithelium forming pedestal-like structures termed A/E lesions (86). Two of these virulence proteins are central for this virulence strategy: the adhesin Intimin expressed on the bacterial surface and the T3SS-injected Translocated Intimin Receptor (TIR), which provides a docking ligand for Intimin on the host epithelial surface $(89,90)$. The attachment of $C$. rodentium, in combination with the secretion of many additional virulence proteins, leads to colonic hyperplasia, observed readily during the peak of infection as larger intestinal crypt length and increased colon weight.

Several reports have shown that NOD1 and NOD2 are able to sense $C$. rodentium both in vitro and in vivo $(75,91,92)$. In the absence of NOD2, C. rodentium reaches a higher intestinal abundance as compared to wild-type mice. At the early stages of infection, NOD2 signaling was shown to activate the CCL2/CCR2 axis that resulted in the recruitment of inflammatory monocytes to the site of infection, which initiated IL-12-mediated bacterial clearance. Interestingly, NOD2-activation took place in intestinal stromal cells and not immune cells. NOD2-deficiency led to lower inflammation at the early stages of infection, but more severe colitis later, as a result of reduced clearance and higher bacterial abundance in the intestine (92). In a different study, NOD1 and NOD2 had redundant roles in the protection against $C$. rodentium infection and mediated IL-6-dependent IL-17 production in the cecum at early time point (1-4 days after infection). The observed effect on infection was similar; lower initial inflammatory responses but increased levels of bacterial dissemination to the spleen in the second week of infection (75). NOD1/NOD2 signaling was shown to occur mostly in the radio-resistant compartment, but a role for stromal cells was not further investigated. Although it is expected that peptidoglycan is the major $C$. rodentium-derived ligand of NOD1 and NOD2, T3SS-injected effector proteins may play a role too, as was shown previously for the Salmonella effector protein SopE (13). Indeed EspT, which targets small GTPases to induce membrane rearrangement in a similar way as SopE, was shown to induce NF- $\mathrm{B}, \mathrm{ERK} 1 / 2$ and JNK activation, common signaling pathways activated after NOD1/2 signaling (93). Future studies will determine to what extent effector-mediated NLR activation contributes to colonization and bacterial clearance.

Caspase-1/Caspase-11-deficient mice were found to be hypersusceptible for $C$. rodentium infection, as determined by increased intestinal bacterial loads, colitis, and hyperplasia (94). Both NLRP3 and NLRC4-deficient mice, as well as mice lacking IL-1 $\beta$ and IL-18, showed similar phenotypes, suggesting an important role for the NLRP3/NLRC4/IL-1 $\beta /$ IL-18 axis in the control of $C$. rodentium. In a different study, a similar but stronger phenotype was observed in IL-1R-deficient mice, which mostly succumb to infection within 2 weeks (95). In contrast to what was seen in IL-18-deficient mice, neutralizing this cytokine with antibodies had limited to no effect, implicating IL- $1 \beta$ or IL- $1 \alpha$ as the critical cytokines that mediated protection against $C$. rodentium. IL-1R signaling during $C$. rodentium infection led to IFN- $\gamma$ and IL- 6 production in the colon, which mediated epithelial repair and maintained barrier function. While bacterial loads remained the same, more bacteria disseminated to the liver in the absence of these cytokines. Like Salmonella and most other Gram-negative bacteria, C. rodentium is able to activate the non-canonical Caspase-11/NLRP3 inflammasome in cultured bone-marrow macrophages, which occurred in a T3SSindependent $(31,94)$. The activation of the Caspase-11/NLRP3 non-canonical inflammasome during infection was evident when examining Caspase-11- and TRIF-deficient mice, which were both more susceptible for $C$. rodentium infection (96). Interestingly, while NLRC4 seems to be activated by $C$. rodentium in vivo, bonemarrow macrophages did not sense the T3SS of $C$. rodentium during in vitro studies. Whether this is due to tightly regulated T3SS expression or host cell tropism/specificity remains to be determined.

\section{HELICOBACTER PYLORI}

The Gram-negative bacterium Helicobacter pylori ( $H$. pylori) colonizes the gastric mucosa of $\sim 50 \%$ of the world's population, although substantial variation exists between countries (97). The majority of people infected by H. pylori do not show any symptoms, despite local chronic inflammatory responses induced by the bacterium. However, in a subset of patients, this inflammatory response drives the formation of gastric or duodenal ulcers that can lead to the development of mucosa-associated lymphoid tissue lymphomas and gastric adenocarcinomas (98-100).

In order to survive in the challenging gastric niche and enable persistent colonization, $H$. pylori is highly optimized to evade host antimicrobial strategies. For instance, after ingestion $H$. pylori secretes urease, which increases the gastric $\mathrm{pH}$ and reduces mucus viscosity, enabling rapid penetration of the gastric mucus layer and colonization in close proximity to the $\mathrm{pH}$ neutral epithelial cells $(99,101)$. Also, H. pylori expresses a modified LPS and flagellin to evade the recognition of TLR4 and TLR5, and has adopted several mechanisms to counteract the effects of host-produced reactive oxygen species $(102,103)$. Finally, the secreted pore-forming toxin VacA induces epithelial cell apoptosis and inhibits T-cell activation and proliferation (104). In contrast to immune evasion, a subset of $H$. pylori strains also actively induces inflammatory responses by means of the T4SS-mediated delivery of the effector protein CagA. CagA modifies multiple intracellular signaling pathways of host cells and is linked to the development of gastric cancer.

While immune evasion appears to be an important part of the $H$. pylori life cycle, genetic association studies revealed that mutations in NOD1, NOD2, and IL-1 $\beta$ may be associated with increased risk for the development of gastric cancer, suggesting that NLRs play a role in controlling $H$. pylori during human infection (105-107). In addition, several NLR family members have been shown to sense the bacterium and impact on infection or colonization, both in in vitro cell culture and in vivo murine models. In a manner analogous to the "leakage" of flagellin through the T3SS in Salmonella, peptidoglycan fragments were found to enter the host cytosol through the T4SS, where they were subsequently sensed by NOD1 and initiated NF- $\mathrm{B}$-mediated inflammatory responses (108). NOD1 activation was also observed by 
peptidoglycan present in secreted bacterial outer membrane vesicles that were taken up by host cells (109). H. pylori was shown to induce the secretion of IL- $1 \beta$ and IL-18 both in vitro and in vivo $(110,111)$. As compared to wild-type mice, Caspase-1/Caspase11-deficient mice showed decreased numbers of Helicobacter in the stomach, higher expression of IL-17, and aggravated gastric immunopathology, which was phenocopied by IL-18 and IL-18R, but not IL-1R deficient mice. Loss of IL-18 signaling in dendritic cells was subsequently shown to result in reduced levels of regulatory $\mathrm{T}$-cells and stronger $\mathrm{T}$-cell-mediated antibacterial responses $(110,112)$. In contrast, different groups reported that Caspase-1/Caspase-11, ASC, IL-1 $\beta$, and IL-1R-deficient mice were impaired in the clearance of $H$. pylori from the stomach, displayed decreased gastritis and lower levels of IL-1 $\beta$ and IL-18 $(111,113)$. While the cause of the discrepancies between these different reports is currently unknown, it appears that $H$. pylori strives for the ideal level of inflammasome activation: enough IL18 and IL- $1 \beta$ to induce regulatory T-cells and decrease gastric acid production, respectively (114), but not so much IL-1 $\beta$ as to lead to T-cell mediated clearance. The nature of the inflammasome NLR that is activated by Helicobacter remains unclear. While in cultured dendritic cells NLRP3 was crucial for IL- $1 \beta$ secretion in a T4SS-dependent/CagA-VacA-independent manner, this NLR did not play a role during murine infection.

\section{THE INTESTINAL MICROBIOTA AND NLR-MEDIATED DISORDERS}

The intestinal microbiota is predicted to consist of $\sim 100$ different bacterial species per person, and displays great variability between individuals (115). Alterations in the composition of the microbiota have been shown to dramatically impact disease susceptibility and progression. Therefore, controlling and (re)shaping the "healthy" microbiota is a crucial function of the intestinal immune system. The role of NLRs in this process is only beginning to be unraveled.

Lack of appropriate immunological control may switch a healthy microbiota into a pathogenic one, as exemplified by mice lacking NLRP6. NLRP6-deficient mice show increased levels of intestinal inflammation during DSS-induced colitis and develop more severe colorectal cancer in a model of colitis-dependent tumorigenesis $(36,39,40,116)$. A potential mechanism was provided by the finding that NLRP6 acts as a negative regulator of $\mathrm{NF}-\kappa \mathrm{B}$ and MAPK activation, and reduces the levels of cytokines and chemokines during infections with intestinal pathogens or epithelial barrier breach as observed during experimental models of colitis (38). More severe and prolonged inflammation in NLRP6-deficient mice results in increased levels of intestinal epithelial proliferation and increased tissue repair, which was shown to be CCL5 and IL-6 dependent $(36,39,40,116)$. The actions of NLRP6 do not seem limited to infectious or damaging episodes, as NLRP6-deficient mice already display continuous low level inflammation in the steady state, suggesting an interaction with the microbiota (36). 16S rRNA sequencing analysis of the microbiota revealed that NLRP6-deficient mice harbor a dysbiotic, colitogenic microbiota that showed a high relative abundance of Prevotellaceae species, that was transmissible to wild-type control mice. Similarly, lack of NLRP6-mediated control of the microbiota induced non-alcoholic fatty liver disease and obesity in mice and increased colorectal cancer, all of which were transmissible through microbiota transfer to wild-type mice $(116,117)$.

NLRP12 and NLRP6 may play similar roles in the control of intestinal homeostasis. Like NLRP6, NLRP12-deficiency leads to uncontrolled NF- $\kappa \mathrm{B}$ signaling and subsequent inflammation and intestinal cell proliferation. Although extensive analysis of the composition of the intestinal microbiota of NLRP12-deficient mice has not been reported, the lack of this NLR might have major effects on the microbiota, either directly through sensing microbial products, or indirectly through the induction of an inflammatory environment via NF-кB dysregulation.

While systemic peptidoglycan from the intestinal microbiota was shown to boost the development of the intestinal immune system and prime immune responses via NOD1 in the bone-marrow in mice $(115,118)$, NOD1, like NOD2, does not dramatically influence the composition of the microbiota under homeostatic conditions (119). However, during DSS-induced colitis, the murine model of inflammatory bowel disease (IBD) that is driven by the microbiota, NOD1/NOD2-deficiency led to greater susceptibility to colitis (120). Similarly, mutations in NOD2 and NOD1 in humans are associated with susceptibility to Crohn's disease and IBD, respectively (121-123). The role of NLRP3 in controlling the microbiota has been rather controversial. Initially, NLRP3 was reported to have a key role in protecting intestinal homeostasis, as NLRP3-deficient mice were shown to have an altered microbiota and displayed increased susceptibility to DSS-colitis $(124,125)$ and tumorigenesis (126). However, NLRP3-deficiency led to resistance to DSS-colitis in a different study (127). As the DSS-colitis model is highly dependent on the microbiota, differential compositions of the microbiota may explain the varying outcomes in these studies. Indeed, co-housing NLRP3-deficient mice with wild-type mice, which equalized the intestinal microbiota, also equalized the inflammatory responses and disease in both mice (128). In humans, the role of NLRP3 in Crohn's is equally confusing; polymorphisms associated with NLRP3 were shown to contribute to susceptibility to Crohn's disease $(129,130)$, but did not replicate in a separate study (131). More detailed investigation of the interactions between specific members of the microbiota and NLRs may provide deeper insights in the function of NLRs in controlling and shaping the microbiota in health and disease.

\section{CONCLUDING REMARKS}

Nod-like receptors are crucial components of the intestinal innate immune system, controlling both the commensal microbiota as well as enteropathogenic bacterial infections. While a growing body of scientific evidence now provides clear insight into the role of NLRs in controlling intestinal bacteria, several conflicting reports highlight the importance of precisely controlling experimental conditions like bacterial growth phase and the intestinal microbiota between wild-type and NLR-deficient mice. Several key questions still remain unanswered, suck as the nature of the ligands for NLRP6 and NLRP12, the interplay between NLRs and adaptive immunity in the intestine, the potential role for other NLRs like NLRP7 (which senses bacterial lipopeptides in human cells), NLRP10 (which controls adaptive immune responses), and NLRC3 (which down-regulates NF- $\kappa$ B), and the role of NLRs in 
human diseases. Future research will undoubtedly shed more light on these interesting new subjects.

\section{ACKNOWLEDGMENTS}

We wish to thank members of the Flavell lab for critically reading the manuscript. This work was supported by the Howard Hughes Medical Institute (Richard A. Flavell), a Department of Defense Grant (W81XWH-11-1-0745) (Richard A. Flavell) and a Rubicon Fellowship from the Netherlands Organization of Scientific Research (NWO) (Marcel R. de Zoete).

\section{REFERENCES}

1. Costello EK, Lauber CL, Hamady M, Fierer N, Gordon JI, Knight R. Bacterial community variation in human body habitats across space and time. Science (2009) 326(5960):1694-7. doi:10.1126/science.1177486

2. Lozupone CA, Stombaugh JI, Gordon JI, Jansson JK, Knight R. Diversity, stability and resilience of the human gut microbiota. Nature (2012) 489(7415):220-30. doi:10.1038/nature11550

3. Hansson GC. Role of mucus layers in gut infection and inflammation. Curr Opin Microbiol (2012) 15(1):57-62. doi:10.1016/j.mib.2011.11.002

4. Ashida H, Ogawa M, Kim M, Mimuro H, Sasakawa C. Bacteria and host interactions in the gut epithelial barrier. Nat Chem Biol (2011) 8(1):36-45. doi:10.1038/nchembio.741

5. Palm NW, Medzhitov R. Pattern recognition receptors and control of adaptive immunity. Immunol Rev (2009) 227(1):221-33. doi:10.1111/j.1600-065X. 2008.00731.x

6. Ray K, Marteyn B, Sansonetti PJ, Tang CM. Life on the inside: the intracellular lifestyle of cytosolic bacteria. Nat Rev Microbiol (2009) 7(5):333-40. doi:10.1038/nrmicro2112

7. Girardin SE, Boneca IG, Carneiro LA, Antignac A, Jéhanno M, Viala J, et al. Nod1 detects a unique muropeptide from gram-negative bacterial peptidoglycan. Science (2003) 300(5625):1584-7. doi:10.1126/science.1084677

8. Girardin SE, Boneca IG, Viala J, Chamaillard M, Labigne A, Thomas G, et al. Nod2 is a general sensor of peptidoglycan through muramyl dipeptide (MDP) detection. J Biol Chem (2003) 278(11):8869-72. doi:10.1074/jbc.C200651200

9. Kobayashi K, Inohara N, Hernandez LD, Galán JE, Núñez G, Janeway CA, et al. RICK/Rip2/CARDIAK mediates signalling for receptors of the innate and adaptive immune systems. Nature (2002) 416(6877):194-9. doi:10.1038/ $416194 \mathrm{a}$

10. Moreira LO, Zamboni DS. NOD1 and NOD2 signaling in infection and inflammation. Front Immunol (2012) 3:328. doi:10.3389/fimmu.2012.00328

11. Wagner RN, Proell M, Kufer TA, Schwarzenbacher R. Evaluation of Nod-like receptor (NLR) effector domain interactions. PLoS One (2009) 4(4):e4931. doi:10.1371/journal.pone.0004931

12. Travassos LH, Carneiro LA, Ramjeet M, Hussey S, Kim Y-G, Magalhães JG, et al. Nod1 and Nod2 direct autophagy by recruiting ATG16L1 to the plasma membrane at the site of bacterial entry. Nat Immunol (2009) 11(1):55-62. doi:10.1038/ni.1823

13. Keestra AM, Winter MG, Auburger JJ, Fräßle SP, Xavier MN, Winter SE, et al. Manipulation of small Rho GTPases is a pathogen-induced process detected by NOD1. Nature (2013) 496(7444):233-7. doi:10.1038/nature12025

14. Hu Z, Yan C, Liu P, Huang Z, Ma R, Zhang C, et al. Crystal structure of NLRC4 reveals its autoinhibition mechanism. Science (2013) 341(6142):172-5. doi:10.1126/science. 1236381

15. Qu Y, Misaghi S, Izrael-Tomasevic A, Newton K, Gilmour LL, Lamkanfi M, et al. Phosphorylation of NLRC4 is critical for inflammasome activation. Nature (2012) 490(7421):539-42. doi:10.1038/nature11429

16. Franchi L, Amer A, Body-Malapel M, Kanneganti T-D, Özören N, Jagirdar R, et al. Cytosolic flagellin requires Ipaf for activation of caspase- 1 and interleukin $1 \beta$ in Salmonella-infected macrophages. Nat Immunol (2006) 7(6):576-82. doi:10.1038/ni1346

17. Miao EA, Alpuche-Aranda CM, Dors M, Clark AE, Bader MW, Miller SI, et al. Cytoplasmic flagellin activates caspase- 1 and secretion of interleukin $1 \beta$ via Ipaf. Nat Immunol (2006) 7(6):569-75. doi:10.1038/ni1344

18. Molofsky AB, Byrne BG, Whitfield NN, Madigan CA, Fuse ET, Tateda K, et al. Cytosolic recognition of flagellin by mouse macrophages restricts Legionella pneumophila infection. J Exp Med (2006) 203(4):1093-104. doi:10.1084/jem. 20051659

19. Miao EA, Mao DP, Yudkovsky N, Bonneau R, Lorang CG, Warren SE, et al. Innate immune detection of the type III secretion apparatus through the NLRC4 inflammasome. Proc Natl Acad Sci U S A (2010) 107(7):3076-80. doi:10.1073/pnas.0913087107

20. Zhao Y, Yang J, Shi J, Gong Y-N, Lu Q, Xu H, et al. The NLRC4 inflammasome receptors for bacterial flagellin and type III secretion apparatus. Nature (2011) 477(7366):596-600. doi:10.1038/nature10510

21. Kofoed EM, Vance RE. Innate immune recognition of bacterial ligands by NAIPs determines inflammasome specificity. Nature (2011) 477(7366):592-5. doi:10.1038/nature10394

22. Halff EF, Diebolder CA, Versteeg M, Schouten A, Brondijk THC, Huizinga EG. Formation and structure of a NAIP5-NLRC4 inflammasome induced by direct interactions with conserved $\mathrm{N}$-and C-terminal regions of flagellin.J Biol Chem (2012) 287(46):38460-72. doi:10.1074/jbc.M112.393512

23. Hoffman HM, Mueller JL, Broide DH, Wanderer AA, Kolodner RD. Mutation of a new gene encoding a putative pyrin-like protein causes familial cold autoinflammatory syndrome and Muckle-Wells syndrome. Nat Genet (2001) 29(3):301-5. doi:10.1038/ng756

24. Franchi L, Muñoz-Planillo R, Núñez G. Sensing and reacting to microbes through the inflammasomes. Nat Immunol (2012) 13(4):325-32. doi:10.1038/ ni. 2231

25. Shimada K, Crother TR, Karlin J, Dagvadorj J, Chiba N, Chen S, et al. Oxidized mitochondrial DNA activates the NLRP3 inflammasome during apoptosis. Immunity (2012) 36(3):401-14. doi:10.1016/j.immuni.2012.01.009

26. Zhou R, Tardivel A, Thorens B, Choi I, Tschopp J. Thioredoxin-interacting protein links oxidative stress to inflammasome activation. Nat Immunol (2009) 11(2):136-40. doi:10.1038/ni.1831

27. Murakami T, Ockinger J, Yu J, Byles V, McColl A, Hofer AM, et al. Critical role for calcium mobilization in activation of the NLRP3 inflammasome. Proc Natl Acad Sci U S A (2012) 109(28):11282-7. doi:10.1073/pnas.1117765109

28. Iyer SS, He Q, Janczy JR, Elliott EI, Zhong Z, Olivier AK, et al. Mitochondrial cardiolipin is required for Nlrp3 inflammasome activation. Immunity (2013) 39(2):311-23. doi:10.1016/j.immuni.2013.08.001

29. Compan V, Baroja-Mazo A, López-Castejón G, Gomez AI, Martínez CM, Angosto D, et al. Cell volume regulation modulates NLRP3 inflammasome activation. Immunity (2012) 37(3):487-500. doi:10.1016/j.immuni.2012.06.013

30. Munoz-Planillo R, Kuffa P, Martinez-Colon G, Smith BL, Rajendiran TM, Nunez G. $\mathrm{K}(+)$ efflux is the common trigger of NLRP3 inflammasome activation by bacterial toxins and particulate matter. Immunity (2013) 38(6):1142-53. doi:10.1016/j.immuni.2013.05.016

31. Kayagaki N, Warming S, Lamkanfi M, Walle LV, Louie S, Dong J, et al. Non-canonical inflammasome activation targets caspase-11. Nature (2011) 479(7371):117-21. doi:10.1038/nature10558

32. Rathinam VA, Vanaja SK, Waggoner L, Sokolovska A, Becker C, Stuart LM, et al. TRIF licenses caspase-11-dependent NLRP3 inflammasome activation by gram-negative bacteria. Cell (2012) 150(3):606-19. doi:10.1016/j.cell.2012. 07.007

33. Kayagaki N, Wong MT, Stowe IB, Ramani SR, Gonzalez LC, AkashiTakamura S, et al. Noncanonical inflammasome activation by intracellular LPS independent of TLR4. Science (2013) 341(6151):1246-9. doi:10.1126/science. 1240248

34. Grenier JM, Wang L, Manji GA, Huang W-J, Al-Garawi A, Kelly R, et al. Functional screening of five PYPAF family members identifies PYPAF5 as a novel regulator of NF-кB and caspase-1. FEBS Lett (2002) 530(1):73-8. doi:10.1016/S0014-5793(02)03416-6

35. Lech M, Avila-Ferrufino A, Skuginna V, Susanti HE, Anders H-J. Quantitative expression of RIG-like helicase, NOD-like receptor and inflammasomerelated mRNAs in humans and mice. Int Immunol (2010) 22(9):717-28. doi:10.1093/intimm/dxq058

36. Elinav E, Strowig T, Kau AL, Henao-Mejia J, Thaiss CA, Booth CJ, et al. NLRP6 inflammasome regulates colonic microbial ecology and risk for colitis. Cell (2011) 145(5):745-57. doi:10.1016/j.cell.2011.04.022

37. Sun Y, Zhang M, Chen CC, Gillilland M, III, Sun X, El-Zaatari M, et al. Stress-induced corticotropin-releasing hormone-mediated NLRP6 inflammasome inhibition and transmissible enteritis in mice. Gastroenterology (2013). 144(7):1478-87.e8. doi:10.1053/j.gastro.2013.02.038 
38. Anand PK, Malireddi RS, Lukens JR, Vogel P, Bertin J, Lamkanfi M, et al. NLRP6 negatively regulates innate immunity and host defence against bacterial pathogens. Nature (2012) 488(7411):389-93. doi:10.1038/nature11250

39. Normand S, Delanoye-Crespin A, Bressenot A, Huot L, Grandjean T, PeyrinBiroulet L, et al. Nod-like receptor pyrin domain-containing protein 6 (NLRP6) controls epithelial self-renewal and colorectal carcinogenesis upon injury. Proc Natl Acad Sci U S A (2011) 108(23):9601-6. doi:10.1073/pnas. 1100981108

40. Chen GY, Liu M, Wang F, Bertin J, Núñez G. A functional role for Nlrp6 in intestinal inflammation and tumorigenesis. J Immunol (2011) 186(12):7187-94. doi:10.4049/jimmunol.1100412

41. Wang L, Manji GA, Grenier JM, Al-Garawi A, Merriam S, Lora JM, et al. PYPAF7, a novel PYRIN-containing Apaf1-like protein that regulates activation of NF-кB and caspase-1-dependent cytokine processing. J Biol Chem (2002) 277(33):29874-80. doi:10.1074/jbc.M203915200

42. Williams KL, Taxman DJ, Linhoff MW, Reed W, Ting JP-Y. Cutting edge: monarch-1: a pyrin/nucleotide-binding domain/leucine-rich repeat protein that controls classical and nonclassical MHC class I genes. J Immunol (2003) 170(11):5354-8.

43. Lich JD, Williams KL, Moore CB, Arthur JC, Davis BK, Taxman DJ, et al. Monarch-1 suppresses non-canonical NF-kappaB activation and p52-dependent chemokine expression in monocytes. J Immunol (2007) 178(3):1256-60.

44. Williams KL, Lich JD, Duncan JA, Reed W, Rallabhandi P, Moore C, et al. The CATERPILLER protein monarch-1 is an antagonist of toll-like receptor-, tumor necrosis factor alpha-, and Mycobacterium tuberculosis-induced proinflammatory signals. J Biol Chem (2005) 280(48):39914-24. doi:10.1074/jbc. M502820200

45. Arthur JC, Lich JD, Ye Z, Allen IC, Gris D, Wilson JE, et al. Cutting edge: NLRP12 controls dendritic and myeloid cell migration to affect contact hypersensitivity. J Immunol (2010) 185(8):4515-9. doi:10.4049/jimmunol.1002227

46. Zaki MH, Vogel P, Malireddi R, Body-Malapel M, Anand PK, Bertin J, et al. The NOD-like receptor NLRP12 attenuates colon inflammation and tumorigenesis. Cancer Cell (2011) 20(5):649-60. doi:10.1016/j.ccr.2011.10.022

47. Allen IC, Wilson JE, Schneider M, Lich JD, Roberts RA, Arthur JC, et al. NLRP12 suppresses colon inflammation and tumorigenesis through the negative regulation of noncanonical NF-кB signaling. Immunity (2012) 36(5):742-54. doi:10.1016/j.immuni.2012.03.012

48. DeYoung KL, Ray ME, Su YA, Anzick SL, Johnstone RW, Trapani JA, et al. Cloning a novel member of the human interferon-inducible gene family associated with control of tumorigenicity in a model of human melanoma. Oncogene (1997) 15(4):453. doi:10.1038/sj.onc.1201206

49. Roberts TL, Idris A, Dunn JA, Kelly GM, Burnton CM, Hodgson S, et al. HIN200 proteins regulate caspase activation in response to foreign cytoplasmic DNA. Science (2009) 323(5917):1057-60. doi:10.1126/science.1169841

50. Hornung V, Ablasser A, Charrel-Dennis M, Bauernfeind F, Horvath G, Caffrey DR, et al. AIM2 recognizes cytosolic dsDNA and forms a caspase-1activating inflammasome with ASC. Nature (2009) 458(7237):514-8. doi:10. 1038/nature07725

51. Fernandes-Alnemri T, Yu J-W, Datta P, Wu J, Alnemri ES. AIM2 activates the inflammasome and cell death in response to cytoplasmic DNA. Nature (2009) 458(7237):509-13. doi:10.1038/nature07710

52. Bürckstümmer T, Baumann C, Blüml S, Dixit E, Dürnberger G, Jahn H, et al. An orthogonal proteomic-genomic screen identifies AIM2 as a cytoplasmic DNA sensor for the inflammasome. Nat Immunol (2009) 10(3):266-72. doi:10.1038/ni.1702

53. Sauer J-D, Witte CE, Zemansky J, Hanson B, Lauer P, Portnoy DA. Listeria monocytogenes triggers AIM2-mediated pyroptosis upon infrequent bacteriolysis in the macrophage cytosol. Cell Host Microbe (2010) 7(5):412-9. doi:10.1016/j.chom.2010.04.004

54. Singh A, Rahman T, Malik M, Hickey AJ, Leifer CA, Hazlett KR, et al. Discordant results obtained with Francisella tularensis during in vitro and in vivo immunological studies are attributable to compromised bacterial structural integrity. PLoS One (2013) 8(3):e58513. doi:10.1371/journal.pone.0058513

55. Ge J, Gong Y-N, Xu Y, Shao F. Preventing bacterial DNA release and absent in melanoma 2 inflammasome activation by a Legionella effector functioning in membrane trafficking. Proc Natl Acad Sci U S A (2012) 109(16):6193-8. doi:10.1073/pnas.1117490109
56. Jin T, Perry A, Jiang J, Smith P, Curry JA, Unterholzner L, et al. Structures of the HIN domain: DNA complexes reveal ligand binding and activation mechanisms of the AIM2 inflammasome and IFI16 receptor. Immunity (2012) 36(4):561-71. doi:10.1016/j.immuni.2012.02.014

57. Jin T, Perry A, Smith P, Jiang J, Xiao TS. Structure of the absent in melanoma 2 (AIM2) Pyrin domain provides insights into the mechanisms of AIM2 autoinhibition and inflammasome assembly. J Biol Chem (2013) 288(19):13225-35. doi:10.1074/jbc.M113.468033

58. Newell DG, Koopmans M, Verhoef L, Duizer E, Aidara-Kane A, Sprong H, et al. Food-borne diseases - the challenges of 20 years ago still persist while new ones continue to emerge. Int J Food Microbiol (2010) 139(Suppl 1):S3-15. doi:10.1016/j.ijfoodmicro.2010.01.021

59. Sur D, Ochiai RL, Bhattacharya SK, Ganguly NK, Ali M, Manna B, et al. A cluster-randomized effectiveness trial of Vi typhoid vaccine in India. N Engl J Med (2009) 361(4):335-44. doi:10.1056/NEJMoa0807521

60. Majowicz SE, Musto J, Scallan E, Angulo FJ, Kirk M, O’Brien SJ, et al. The global burden of nontyphoidal Salmonella gastroenteritis. Clin Infect Dis (2010) 50(6):882-9. doi:10.1086/650733

61. Stecher B, Barthel M, Schlumberger MC, Haberli L, Rabsch W, Kremer M, et al. Motility allows S. typhimurium to benefit from the mucosal defence. Cell Microbiol (2008) 10(5):1166-80. doi:10.1111/j.1462-5822.2008.01118.x

62. Haraga A, Ohlson MB, Miller SI. Salmonellae interplay with host cells. Nat Rev Microbiol (2008) 6(1):53-66. doi:10.1038/nrmicro1788

63. Diehl GE, Longman RS, Zhang J-X, Breart B, Galan C, Cuesta A, et al. Microbiota restricts trafficking of bacteria to mesenteric lymph nodes by CX3CR1hi cells. Nature (2013) 494(7435):116-20. doi:10.1038/nature11809

64. Kaiser P, Diard M, Stecher B, Hardt WD. The streptomycin mouse model for Salmonella diarrhea: functional analysis of the microbiota, the pathogen's virulence factors, and the host's mucosal immune response. Immunol Rev (2012) 245(1):56-83. doi:10.1111/j.1600-065X.2011.01070.x

65. Winter SE, Thiennimitr P, Winter MG, Butler BP, Huseby DL, Crawford RW, et al. Gut inflammation provides a respiratory electron acceptor for Salmonella. Nature (2010) 467(7314):426-9. doi:10.1038/nature09415

66. Hisamatsu T, Suzuki M, Reinecker HC, Nadeau WJ, McCormick BA, Podolsky DK. CARD15/NOD2 functions as an antibacterial factor in human intestinal epithelial cells. Gastroenterology (2003) 124(4):993-1000. doi:10.1053/gast. 2003.50153

67. Homer CR, Kabi A, Marina-Garcia N, Sreekumar A, Nesvizhskii AI, Nickerson KP, et al. A dual role for receptor-interacting protein kinase 2 (RIP2) kinase activity in nucleotide-binding oligomerization domain 2 (NOD2)dependent autophagy. J Biol Chem (2012) 287(30):25565-76. doi:10.1074/jbc. M111.326835

68. Yamamoto-Furusho JK, Barnich N, Hisamatsu T, Podolsky DK. MDPNOD2 stimulation induces HNP-1 secretion, which contributes to NOD2 antibacterial function. Inflamm Bowel Dis (2010) 16(5):736-42. doi:10.1002/ ibd. 21144

69. Le Bourhis L, Magalhaes JG, Selvanantham T, Travassos LH, Geddes K, Fritz JH, et al. Role of Nod1 in mucosal dendritic cells during Salmonella pathogenicity island 1-independent Salmonella enterica serovar typhimurium infection. Infect Immun (2009) 77(10):4480-6. doi:10.1128/IAI.00519-09

70. Keestra AM, Winter MG, Klein-Douwel D, Xavier MN, Winter SE, Kim A, et al. A Salmonella virulence factor activates the NOD1/NOD2 signaling pathway. MBio (2011) 2(6). doi:10.1128/mBio.00266-11

71. Perez-Lopez A, Rosales-Reyes R, Alpuche-Aranda CM, Ortiz-Navarrete V. Salmonella downregulates Nod-like receptor family CARD domain containing protein 4 expression to promote its survival in B cells by preventing inflammasome activation and cell death. J Immunol (2013) 190(3):1201-9. doi:10.4049/jimmunol.1200415

72. Kupz A, Guarda G, Gebhardt T, Sander LE, Short KR, Diavatopoulos DA, et al. NLRC4 inflammasomes in dendritic cells regulate noncognate effector function by memory CD8+ T cells. Nat Immunol (2012) 13(2):162-9. doi:10.1038/ni.2195

73. Broz P, Ruby T, Belhocine K, Bouley DM, Kayagaki N, Dixit VM, et al. Caspase11 increases susceptibility to Salmonella infection in the absence of caspase-1. Nature (2012) 490(7419):288-91. doi:10.1038/nature11419

74. Geddes K, Rubino S, Streutker C, Cho JH, Magalhaes JG, Le Bourhis L, et al. Nod1 and Nod2 regulation of inflammation in the Salmonella colitis model. Infect Immun (2010) 78(12):5107-15. doi:10.1128/IAI.00759-10 
75. Geddes K, Rubino SJ, Magalhaes JG, Streutker C, Le Bourhis L, Cho JH, et al. Identification of an innate $\mathrm{T}$ helper type 17 response to intestinal bacterial pathogens. Nat Med (2011) 17(7):837-44. doi:10.1038/nm.2391

76. Bruno VM, Hannemann S, Lara-Tejero M, Flavell RA, Kleinstein SH, Galán JE. Salmonella typhimurium type III secretion effectors stimulate innate immune responses in cultured epithelial cells. PLoS Pathog (2009) 5(8):e1000538. doi:10.1371/journal.ppat.1000538

77. Lara-Tejero M, Sutterwala FS, Ogura Y, Grant EP, Bertin J, Coyle AJ, et al. Role of the caspase- 1 inflammasome in Salmonella typhimurium pathogenesis. J Exp Med (2006) 203(6):1407-12. doi:10.1084/jem.20060206

78. Raupach B, Peuschel S-K, Monack DM, Zychlinsky A. Caspase-1-mediated activation of interleukin- $1 \beta$ (IL-1 $\beta$ ) and IL-18 contributes to innate immune defenses against Salmonella enterica serovar typhimurium infection. Infect Immun (2006) 74(8):4922-6. doi:10.1128/IAI.00417-06

79. Broz P, Newton K, Lamkanfi M, Mariathasan S, Dixit VM, Monack DM. Redundant roles for inflammasome receptors NLRP3 and NLRC4 in host defense against Salmonella. J Exp Med (2010) 207(8):1745-55. doi:10.1084/ jem.20100257

80. Carvalho FA, Nalbantoglu I, Aitken JD, Uchiyama R, Su Y, Doho GH, et al. Cytosolic flagellin receptor NLRC4 protects mice against mucosal and systemic challenges. Mucosal Immunol (2012) 5(3):288-98. doi:10.1038/mi.2012.8

81. Miao EA, Leaf IA, Treuting PM, Mao DP, Dors M, Sarkar A, et al. Caspase-1induced pyroptosis is an innate immune effector mechanism against intracellular bacteria. Nat Immunol (2010) 11(12):1136-42. doi:10.1038/ni.1960

82. Vijay Kumar M, Carvalho FA, Aitken JD, Fifadara NH, Gewirtz AT. TLR5 or NLRC4 is necessary and sufficient for promotion of humoral immunity by flagellin. Eur J Immunol (2010) 40(12):3528-34. doi:10.1002/eji.201040421

83. Aachoui Y, Leaf IA, Hagar JA, Fontana MF, Campos CG, Zak DE, et al. Caspase-11 protects against bacteria that escape the vacuole. Science (2013) 339(6122):975-8. doi:10.1126/science.1230751

84. Franchi L, Kamada N, Nakamura Y, Burberry A, Kuffa P, Suzuki S, et al. NLRC4driven production of IL-1 [beta] discriminates between pathogenic and commensal bacteria and promotes host intestinal defense. Nat Immunol (2012) 13(5):449-56. doi:10.1038/ni.2263

85. Schmidt MA. LEEways: tales of EPEC, ATEC and EHEC. Cell Microbiol (2010) 12(11):1544-52. doi:10.1111/j.1462-5822.2010.01518.x

86. Mundy R, MacDonald TT, Dougan G, Frankel G, Wiles S. Citrobacter rodentium of mice and man. Cell Microbiol (2005) 7(12):1697-706. doi:10.1111/j. 1462-5822.2005.00625.x

87. Wiles S, Clare S, Harker J, Huett A, Young D, Dougan G, et al. Organ specificity, colonization and clearance dynamics in vivo following oral challenges with the murine pathogen Citrobacter rodentium. Cell Microbiol (2004) 6(10):963-72. doi:10.1111/j.1462-5822.2004.00414.x

88. Bishop AL, Wiles S, Dougan G, Frankel G. Cell attachment properties and infectivity of host-adapted and environmentally adapted Citrobacter rodentium. Microbes Infect (2007) 9(11):1316-24. doi:10.1016/j.micinf.2007.06.006

89. Yang J, Tauschek M, Hart E, Hartland EL, Robins Browne RM. Virulence regulation in Citrobacter rodentium: the art of timing. Microb Biotechnol (2010) 3(3):259-68. doi:10.1111/j.1751-7915.2009.00114.x

90. Celli J, Deng W, Finlay BB. Enteropathogenic Escherichia coli (EPEC) attachment to epithelial cells: exploiting the host cell cytoskeleton from the outside. Cell Microbiol (2000) 2(1):1-9. doi:10.1046/j.1462-5822.2000.00033.x

91. LeBlanc PM, Yeretssian G, Rutherford N, Doiron K, Nadiri A, Zhu L, et al. Caspase-12 modulates NOD signaling and regulates antimicrobial peptide production and mucosal immunity. Cell Host Microbe (2008) 3(3):146-57. doi:10.1016/j.chom.2008.02.004

92. Kim Y-G, Kamada N, Shaw MH, Warner N, Chen GY, Franchi L, et al. The Nod2 sensor promotes intestinal pathogen eradication via the chemokine CCL2-dependent recruitment of inflammatory monocytes. Immunity (2011) 34(5):769-80. doi:10.1016/j.immuni.2011.04.013

93. Raymond B, Crepin VF, Collins JW, Frankel G. The WxxxE effector EspT triggers expression of immune mediators in an Erk/JNK and NF- $\mathrm{B}$-dependent manner. Cell Microbiol (2011) 13(12):1881-93. doi:10.1111/j.1462-5822.2011. 01666.x

94. Liu Z, Zaki MH, Vogel P, Gurung P, Finlay BB, Deng W, et al. Role of inflammasomes in host defense against Citrobacter rodentium infection. J Biol Chem (2012) 287(20):16955-64. doi:10.1074/jbc.M112.358705
95. Lebeis SL, Powell KR, Merlin D, Sherman MA, Kalman D. Interleukin-1 receptor signaling protects mice from lethal intestinal damage caused by the attaching and effacing pathogen Citrobacter rodentium. Infect Immun (2009) 77(2):604-14. doi:10.1128/IAI.00907-08

96. Gurung P, Malireddi RS, Anand PK, Demon D, Walle LV, Liu Z, et al. Toll or interleukin-1 receptor (TIR) domain-containing adaptor inducing interferon$\beta$ (TRIF)-mediated caspase- 11 protease production integrates Toll-like receptor 4 (TLR4) protein-and Nlrp3 inflammasome-mediated host defense against enteropathogens. J Biol Chem (2012) 287(41):34474-83. doi:10.1074/jbc. M112.401406

97. Calvet X, Ramírez Lázaro MJ, Lehours P, Mégraud F. Diagnosis and epidemiology of Helicobacter pylori infection. Helicobacter (2013) 18(s1):5-11. doi:10.1111/hel.12071

98. Cover TL, Blaser MJ. Helicobacter pylori in health and disease. Gastroenterology (2009) 136(6):1863-73. doi:10.1053/j.gastro.2009.01.073

99. Salama NR, Hartung ML, Müller A. Life in the human stomach: persistence strategies of the bacterial pathogen Helicobacter pylori. Nat Rev Microbiol (2013) 11(6):385-99. doi:10.1038/nrmicro3016

100. Wroblewski LE, Peek RM, Wilson KT. Helicobacter pylori and gastric cancer: factors that modulate disease risk. Clin Microbiol Rev (2010) 23(4):713-39. doi:10.1128/CMR.00011-10

101. Celli JP, Turner BS, Afdhal NH, Keates S, Ghiran I, Kelly CP, et al. Helicobacter pylori moves through mucus by reducing mucin viscoelasticity. Proc Natl Acad Sci U S A (2009) 106(34):14321-6. doi:10.1073/pnas.0903438106

102. Cullen TW, Giles DK, Wolf LN, Ecobichon C, Boneca IG, Trent MS. Helicobacter pylori versus the host: remodeling of the bacterial outer membrane is required for survival in the gastric mucosa. PLoS Pathog (2011) 7(12):e1002454. doi:10.1371/journal.ppat.1002454

103. Gewirtz AT, Yu Y, Krishna US, Israel DA, Lyons SL, Peek RM. Helicobacter pylori flagellin evades toll-like receptor 5-mediated innate immunity. J Infect Dis (2004) 189(10):1914-20. doi:10.1086/386289

104. Palframan SL, Kwok T, Gabriel K. Vacuolating cytotoxin A (VacA), a key toxin for Helicobacter pylori pathogenesis. Front Cell Infect Microbiol (2012) 2:92. doi:10.3389/fcimb.2012.00092

105. Rosenstiel P, Hellmig S, Hampe J, Ott S, Till A, Fischbach W, et al. Influence of polymorphisms in the NOD1/CARD4 and NOD2/CARD15 genes on the clinical outcome of Helicobacter pylori infection. Cell Microbiol (2006) 8(7):1188-98. doi:10.1111/j.1462-5822.2006.00701.x

106. Hofner P, Gyulai Z, Kiss ZF, Tiszai A, Tiszlavicz L, Toth G, et al. Genetic polymorphisms of NOD1 and IL-8, but not polymorphisms of TLR4 genes, are associated with Helicobacter pylori-induced duodenal ulcer and gastritis. Helicobacter (2007) 12(2):124-31. doi:10.1111/j.1523-5378.2007.00481.x

107. Sugimoto M, Yamaoka Y, Furuta T. Influence of interleukin polymorphisms on development of gastric cancer and peptic ulcer. World J Gastroenterol (2010) 16(10):1188. doi:10.3748/wjg.v16.i10.1188

108. Viala J, Chaput C, Boneca IG, Cardona A, Girardin SE, Moran AP, et al. Nod1 responds to peptidoglycan delivered by the Helicobacter pylori cag pathogenicity island. Nat Immunol (2004) 5(11):1166-74. doi:10.1038/ni1131

109. Kaparakis M, Turnbull L, Carneiro L, Firth S, Coleman HA, Parkington HC, et al. Bacterial membrane vesicles deliver peptidoglycan to NOD1 in epithelial cells. Cell Microbiol (2010) 12(3):372-85. doi:10.1111/j.1462-5822.2009. 01404.x

110. Hitzler I, Sayi A, Kohler E, Engler DB, Koch KN, Hardt W-D, et al. Caspase-1 has both proinflammatory and regulatory properties in Helicobacter infections, which are differentially mediated by its substrates IL-1 $\beta$ and IL-18. J Immunol (2012) 188(8):3594-602. doi:10.4049/jimmunol.1103212

111. Kim DJ, Park JH, Franchi L, Backert S, Núñez G. The Cag pathogenicity island and interaction between TLR2/NOD2 and NLRP3 regulate IL- $1 \beta$ production in Helicobacter pylori infected dendritic cells. Eur J Immunol (2013) 43(10):2650-8. doi:10.1002/eji.201243281

112. Oertli M, Sundquist M, Hitzler I, Engler DB, Arnold IC, Reuter S, et al. DCderived IL-18 drives Treg differentiation, murine Helicobacter pylori-specific immune tolerance, and asthma protection. J Clin Invest (2012) 122(3):1082. doi:10.1172/JCI61029

113. Benoit BN, Kobayashi M, Kawakubo M, Takeoka M, Sano K, Zou J, et al. Role of ASC in the mouse model of Helicobacter pylori infection. J Histochem Cytochem (2009) 57(4):327-38. doi:10.1369/jhc.2008.952366 
114. Sugimoto M, Furuta T, Yamaoka Y. Influence of inflammatory cytokine polymorphisms on eradication rates of Helicobacter pylori. J Gastroenterol Hepatol (2009) 24(11):1725-32. doi:10.1111/j.1440-1746.2009.06047.x

115. Faith JJ, Guruge JL, Charbonneau M, Subramanian S, Seedorf H, Goodman $\mathrm{AL}$, et al. The long-term stability of the human gut microbiota. Science (2013) 341(6141). doi:10.1126/science.1237439

116. Hu B, Elinav E, Huber S, Strowig T, Hao L, Hafemann A, et al. Microbiotainduced activation of epithelial IL-6 signaling links inflammasome-driven inflammation with transmissible cancer. Proc Natl Acad Sci U S A (2013) 110(24):9862-7. doi:10.1073/pnas.1307575110

117. Henao-Mejia J, Elinav E, Jin C, Hao L, Mehal WZ, Strowig T, et al. Inflammasome-mediated dysbiosis regulates progression of NAFLD and obesity. Nature (2012) 482(7384):179-85. doi:10.1038/nature10809

118. Bouskra D, Brézillon C, Bérard M, Werts C, Varona R, Boneca IG, et al. Lymphoid tissue genesis induced by commensals through NOD1 regulates intestinal homeostasis. Nature (2008) 456(7221):507-10. doi:10.1038/nature07450

119. Robertson SJ, Zhou JY, Geddes K, Rubino SJ, Cho JH, Philpott DJ, et al. Nod1 and Nod2 signaling does not alter the composition of intestinal bacterial communities at homeostasis. Gut Microbes (2013) 4(3):222-31. doi:10.4161/gmic. 24373

120. Natividad JM, Petit V, Huang X, de Palma G, Jury J, Sanz Y, et al. Commensal and probiotic bacteria influence intestinal barrier function and susceptibility to colitis in Nod1-/-; Nod2-/- mice. Inflamm Bowel Dis (2012) 18(8):1434-46. doi:10.1002/ibd.22848

121. Hugot J-P, Chamaillard M, Zouali H, Lesage S, Cézard J-P, Belaiche J, et al. Association of NOD2 leucine-rich repeat variants with susceptibility to Crohn's disease. Nature (2001) 411(6837):599-603. doi:10.1038/35079107

122. Ogura Y, Bonen DK, Inohara N, Nicolae DL, Chen FF, Ramos R, et al. A frameshift mutation in NOD2 associated with susceptibility to Crohn's disease. Nature (2001) 411(6837):603-6. doi:10.1038/35079114

123. Lu W-G, Zou Y-F, Feng X-L, Yuan F-L, Gu Y-L, Li X, et al. Association of NOD1 (CARD4) insertion/deletion polymorphism with susceptibility to IBD: a meta-analysis. World J Gastroenterol (2010) 16(34):4348. doi:10.3748/wjg. v16.i34.4348

124. Hirota SA, Ng J, Lueng A, Khajah M, Parhar K, LiY, et al. NLRP3 inflammasome plays a key role in the regulation of intestinal homeostasis. Inflamm Bowel Dis (2011) 17(6):1359-72. doi:10.1002/ibd.21478

125. Zaki MH, Boyd KL, Vogel P, Kastan MB, Lamkanfi M, Kanneganti T-D. The NLRP3 inflammasome protects against loss of epithelial integrity and mortality during experimental colitis. Immunity (2010) 32(3):379-91. doi:10.1016/j. immuni.2010.03.003
126. Allen IC, TeKippe EM, Woodford R-MT, Uronis JM, Holl EK, Rogers AB, et al. The NLRP3 inflammasome functions as a negative regulator of tumorigenesis during colitis-associated cancer. J Exp Med (2010) 207(5):1045-56. doi:10.1084/jem.20100050

127. Bauer C, Duewell P, Mayer C, Lehr HA, Fitzgerald KA, Dauer M, et al. Colitis induced in mice with dextran sulfate sodium (DSS) is mediated by the NLRP3 inflammasome. Gut (2010) 59(9):1192-9. doi:10.1136/gut.2009. 197822

128. Bauer C, Duewell P, Lehr H-A, Endres S, Schnurr M. Protective and aggravating effects of NLRP3 inflammasome activation in IBD models: influence of genetic and environmental factors. Dig Dis (2012) 30(Suppl 1):82-90. doi:10.1159/000341681

129. Villani A-C, Lemire M, Fortin G, Louis E, Silverberg MS, Collette C, et al. Common variants in the NLRP3 region contribute to Crohn's disease susceptibility. Nat Genet (2008) 41(1):71-6. doi:10.1038/ng.285

130. Schoultz I, Verma D, Halfvarsson J, Törkvist L, Fredrikson M, Sjöqvist U, et al. Combined polymorphisms in genes encoding the inflammasome components NALP3 and CARD8 confer susceptibility to Crohn's disease in Swedish men. Am J Gastroenterol (2009) 104(5):1180-8. doi:10.1038/ajg.2009.29

131. Lewis GJ, Massey DC, Zhang H, Bredin F, Tremelling M, Lee JC, et al. Genetic association between NLRP3 variants and Crohn's disease does not replicate in a large UK panel. Inflamm Bowel Dis (2011) 17(6):1387-91. doi:10.1002/ibd.21499

Conflict of Interest Statement: The authors declare that the research was conducted in the absence of any commercial or financial relationships that could be construed as a potential conflict of interest.

Received: 01 October 2013; accepted: 03 December 2013; published online: 17 December 2013.

Citation: de Zoete MR and Flavell RA (2013) Interactions between Nod-like receptors and intestinal bacteria. Front. Immunol. 4:462. doi: 10.3389/fimmu.2013.00462

This article was submitted to Molecular Innate Immunity, a section of the journal Frontiers in Immunology.

Copyright $(92013$ de Zoete and Flavell. This is an open-access article distributed under the terms of the Creative Commons Attribution License (CC BY). The use, distribution or reproduction in other forums is permitted, provided the original author (s) or licensor are credited and that the original publication in this journal is cited, in accordance with accepted academic practice. No use, distribution or reproduction is permitted which does not comply with these terms. 